\title{
Trust chiefs cause flood of serious cases to GMC
}

The researchers identified six articles from each of two journals-the New England Journal of Medicine and the Lancet-that were prereleased on the journals' websites, and they then matched them with 12 control articles. Using a 10 point scale, 42 general internists rated the articles on importance, ease of applicability, and impact on health outcomes.

The fast-tracked articles on average had slightly higher importance and applicability scores than the controls, but the differences were modest, and five of the 12 controls were considered to be of similar or greater importance than the fast-tracked ones.

The authors concluded that "journals in some instances are not expediting the publication or release of important articles, and in other instances are selecting relatively less important articles for expedited publication. Journals now need to find ways to consistently rate the importance of every submitted article." David Spurgeon Quebec

\section{Australia's detention policy puts refugees' health at risk}

Australia's tough stance on asylum seekers and refugees has come under fire from a broad alliance of the country's main health and medical groups.

The detention of thousands of asylum seekers, including hundreds of children, and the lack of services for thousands of others living in the community are causing serious health problems, the alliance says in a report.

The coalition of 30 groupswhich include the medical colleges, nurses' groups, and the Australian Medical Association-has called for sweeping changes to current policies, warning that they risk creating a generation of deeply troubled young people.

"Australia is now the only western nation that places all informal and undocumented asylum seekers in mandatory detention for unlimited periods of time," the report says.

It warns that Australia is breaching its obligations under the United Nations Convention on the Rights of the Child. Melissa Sweet Sydney

Submission to the Human Rights and Equal Opportunity Commission Inquiry into Children in Immigration Detention is available on the Royal Australasian College of Physicians website: www.racp.edu.au

\section{Psychiatrist settles dispute with Toronto University}

David Healy, the psychiatrist from the University of Wales who sued the University of Toronto for \$C9.4 million (£4.1m \$US6m; $€ 6.6 \mathrm{~m}$ ), claiming violation of academic freedom and defamation as a scientist and physician, has been named visiting professor in the Canadian university's medical faculty. His supporters regard this as a vindication for Dr Healy.

In September 2000, Dr Healy accepted the post of director of the mood and anxiety disorders programme at the university's affiliated Centre for Addiction and Mental Health. After delivering a lecture at the Centre in November 2000, during which he voiced criticisms of psychotropic drugs, the offer was abruptly rescinded. Dr Healy and his supporters believed the rescindment was due to his remarks about the drugs, which included Prozac (fluoxetine), manufactured by Eli Lilly, which donated funds to the centre (BMI 2001;323:591).

University and centre officials denied the decision had anything to do with academic freedom.

The centre's website carries a statement announcing Dr Healy's appointment "the settlement of all litigation and other outstanding disputes."

The joint statement from Dr Healy, the centre, and the university says: "Although Dr Healy believes that his clinical appointment was rescinded because of his November, 2000, speech, Dr Healy accepts assurances that pharmaceutical companies played no role" in rescinding either his clinical or academic appointment.

David Spurgeon Quebec
Katherine Burke London

Nearly two thirds of professional conduct complaints languish for more than a year between committees because of an upsurge in the number of serious cases referred to the General Medical Council.

The GMC has admitted that some "fitness to practise" complaints take over two years to deal with because the Professional Conduct Committee (PCC) cannot keep up with the caseload referred to it.

Fitness to practise figures show that the committee heard only $35 \%$ of conduct cases within a year, compared with a target of $90 \%$ (for cases referred to it by the Preliminary Proceedings Committee between 1 July 2000 and 31 December 2001).

At a preview of the GMC's council meeting next week, chief executive Finlay Scott said that increasingly vigilant trust chiefs and medical directors are causing a flood of serious fitness to practise cases.

Two years ago about 40 cases were in the professional conduct queue compared with 240 cases now, with a "very sharp" increase in waiting times, said Finlay Scott.

"We think that the introduction of clinical governance and other management mechanisms for dealing with poor practice are having the effect of flushing out longstanding problems," he added.

Whereas the GMC takes forward only about one in five of

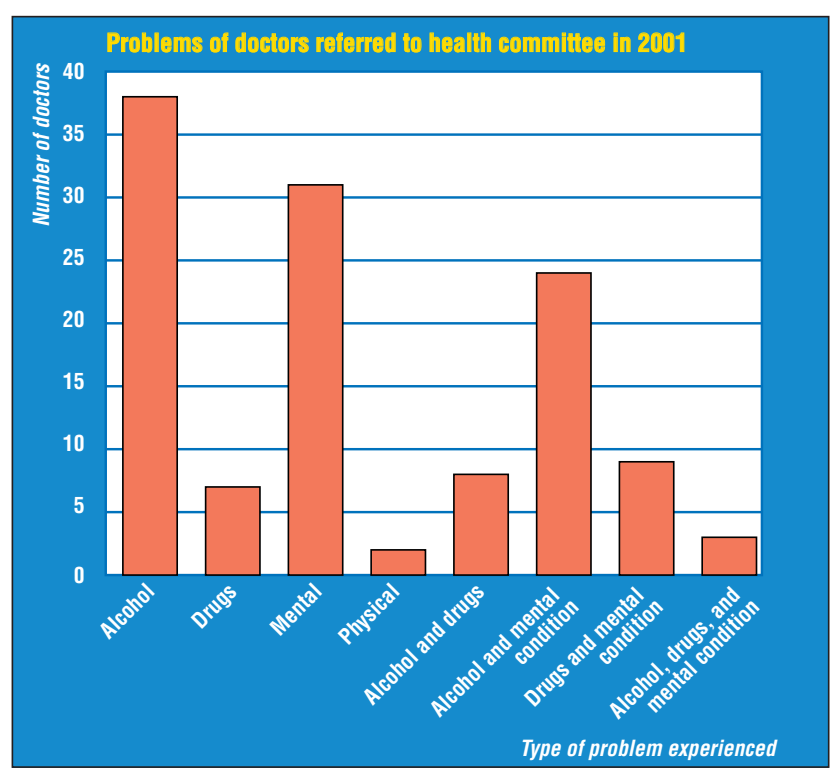

the complaints brought by the general public, it pursues about $70 \%$ of those from health authorities or trusts.

The GMC has responded by expanding the number of PCC panels to six and almost doubling the number of days the committee sits-from 242 days in 2000 to 479 last year. And the council plans to investigate cases more quickly-it has already appointed a second firm of solicitors, and a third firm is to be contracted soon.

"For the first time in quite a number of years we're beginning to make inroads into the backlog. We're pretty confident that by the end of 2002 we will be very close to, if not on target for, getting $90 \%$ of PCC cases heard within a year," said Mr Scott.

Of 122 doctors referred to the council's health committee in 2001 , more than half $(60 \%)$ had problems involving alcohol either on its own or in association with drugs or mental conditions, the council's papers show. - The GMC paid out nearly $£ 1 \mathrm{~m}(\$ 1.5 \mathrm{~m}$; €1.6m) in trustees' travel, accommodation, subsistence, and locum expenses during 2001, the council's accounts show. In addition, trustees received $£ 1.5 \mathrm{~m}$ in attendance allowances, honorariums, and locum payments to related parties. Donald Irvine, former GMC president, received £169393 in attendance allowances and 